\title{
Mukoid dejenerasyon ve menisküs kistleri
}

\author{
Mucoid degeneration and meniscal cysts
}

\author{
Hakan Boya ${ }^{1}$, Halit Pınar ${ }^{2}$ \\ ${ }^{1}$ Başkent Üniversitesi Tıp Fakültesi, Ortopedi ve Travmatoloji Anabilim Dalı, Ankara; Zübeyde Hanım Uygulama ve Araştırma Merkezi, İzmir \\ ${ }^{2}$ Dokuz Eylül Üniversitesi, Tıp Fakültesi, Ortopedi ve Travmatoloji Anabilim Dalı, İzmir
}

Menisküs kistleri, içi mukoid materyal ile dolu, menisküs yapısı içinde veya onunla bağlantılı kistlerdir. Mukoid dejenerasyon (MD) menisküs kistlerinin etiyolojisinde rol alan temel faktördür. İntrameniskal kistin, yırtık veya dejenere menisküs dokusu içinde eklem sıvısının lokal birikimi ile oluştuğuna da inanılır. Parameniskal kistler, eklem sıvısının menisküs yırtığı aracılığı ile (flep yırtığın tek yönlü valf etkisi) parameniskal yumuşak dokulara ulaşması sonucu meydana gelir. Menisküs yapısında vertikal olarak uzanan kollajen liflerin hasarı ile intrameniskal yırtık oluşur ve bu intrameniskal yırtığın içi mukoid materyalle doludur. Bu alandaki MD zemininde oluşmuş intrameniskal yırtık eklemin santraline doğru uzanırsa, ekleme açılır ve dejenere zeminde oluşan horizontal menisküs yırtığı izlenir. Şayet patoloji eklemin periferine yönelirse, mukoid materyal periferde birikerek parameniskal menisküs kisti meydana getirir ve bu kistin intrameniskal yırtıkla doğrudan bağlantısı bulunur. Menisküs yapısındaki bu intrameniskal yırtığın her iki tarafa ilerlemesiyle, horizontal menisküs yırtığının eşlik ettiği parameniskal kist izlenebilir. Klinikte, diz lateral kompartman tutulumu sık izlenir. Menisküs kistleri semptom vermeyebilir (küçük boyutlu kistler); semptomatik olduğunda en önemli yakınma ağrıdır; palpasyonla hassasiyet ve genellikle dizin lateralinde şişlik saptanabilir. Mediyal menisküste kistler genelde menisküs gövdesine yerleştiği için kistik kitlenin oluşumu nadirdir; eğer kist gelişirse mediyal menisküs arka boynuzundan kaynaklanır; genellikle daha büyük olur ve dizin posteromediyalinde palpe edilebilir. Manyetik rezonans (MR) görüntüleme tetkiki, gerek kistin gerekse eşlik eden menisküs yırtığının tanısında önemli rol oynar. Menisküs yırtığının artroskopik tedavisini takiben, içten-dışa ve dıştan-içe yapılan kist dekompresyonu ile uzun dönem takiplerde klinik sonuçlar benzerdir.

Anahtar sözcükler: menisküs; kist; menisküs kisti; mukoid dejenerasyon
These are cysts which contain mucoid material, and are located inside or connected with the meniscus. Mucoid degeneration (MD) is a major factor in the etiology of meniscal cysts. It is also believed that intrameniscal cysts are formed by local accumulation of joint fluid in the torn or degenerated meniscus tissue. Parameniscal cysts occur when the joint fluid reaches the meniscal periphery through the meniscal tear (one-way valve mechanism). Intrameniscal tear is formed by the damage of the collagen fibers extending vertically in the meniscus structure, and this intrameniscal tear is filled with mucoid material. If the intrameniscal tear extends to the central zone, it opens into the joint, and a horizontal meniscal tear is formed in the degenerative zone. If the pathology extends to the periphery of the joint, the mucoid material accumulates in the periphery and forms the parameniscal cyst, and this cyst has a direct connection with the intrameniscal tear. If intrameniscal tear extends to both sides, a parameniscal cyst associated with horizontal meniscal tear is formed. Lateral compartment involvement is frequently observed clinically. Small-sized meniscus cysts may not cause symptoms; the most important complaint is pain in symptomatic patients; tenderness with palpation and swelling in the lateral side of the knee can usually be detected. Medial meniscal masses due to meniscal cysts are rarely seen, because the cysts are located inside the meniscus (stromal mucoid degeneration), and if a cyst develops, it arises from the medial meniscus posterior horn and is palpated as a large swelling posteromedially. Magnetic resonance imaging examination plays an important role in the diagnosis of meniscal cyst and associated meniscus tear. Clinical results are similar in long-term follow-up with cyst decompression done either inside-out or outside-in following arthroscopic treatment of the meniscal tear.

Key words: meniscus; cyst; meniscal cyst, mucoid degeneration

- İletişim adresi: Prof. Dr. Halit Pınar, Dokuz Eylül Üniversitesi, Tıp Fakültesi, Ortopedi ve Travmatoloji Anabilim Dalı, İzmir Tel: 0532 - 4165546 e-posta: halit.pinar@deu.edu.tr

- Geliș tarihi: 1 Mart $2018 \quad$ Kabul tarihi: 1 Mart 2018 


\section{TANIM}

Menisküs kistleri, içi mukoid materyal ile dolu, menisküs yapısı içinde veya onunla bağlantılı kistlerdir. Bununla birlikte, dejenere menisküs yapısı içinde veya çevresinde bulunan, içi sinoviyal sıvı ile dolu kistler olarak da bilinir. ${ }^{[1]}$ Diz ekleminde üç tip menisküs kisti bulunur: intrameniskal kist, parameniskal kist (ekstraartiküler), intra-artiküler kist. ${ }^{[2-4]}$

Menisküs dokusu içinde iki farklı tipte mukoid dejenerasyon (MD) izlenir; stromal MD ve kistik parameniskal MD. Stromal MD'de mukoid materyal (mukoprotein, glikoprotein) hücrelerin çevresinde artış gösterir ve hücreler arasındaki alana doğru hızla yayılarak fibrokartilaj dejenerasyonuna sebep olur. Kistik parameniskal dejenerasyon ise parameniskal alana lokalizedir, menisküs yapısındaki birbiriyle bağlantılı çatlaklar ve yalancı kistlerin varlığı karakteristik özelliğidir. ${ }^{[5,6]}$

\section{ETIYOLOJi}

$M D$, menisküs kistlerinin etiyolojisinde rol alan temel faktördür. ${ }^{[5,6]} \mathrm{MD}$ etiyolojisinden sorumlu tutulan faktörler aynı zamanda menisküs kisti oluşumundan da sorumludur: endojen ve/veya ekzojen travma (artmış mekanik stresler) ${ }^{[5,7-9]}$, menisküsün oluşumu sırasında yapısı içine endotel hücresinin dahil olması ${ }^{[10]}$, kronik enfeksiyonla birlikte olan kanama ${ }^{[11,12]}$, parankimal doku içine olan kanama. ${ }^{[13]}$ Bizim çalışmamızda, bakteriyel enfeksiyonun MD etiyolojisinde rol aldığı gösterilemedi. ${ }^{[14]}$ Apopitoza bağlı hücre ölümü ile oluşan dejenerasyonda ise kollajen ve proteoglikan sentezi baskılanır; bu özelliği ile, hücrelerden mukoid materyal sentezinin arttığı MD'den ayrılır. ${ }^{[15,16]}$ Yaşlanmaya bağlı oluşan menisküs dejenerasyonu fizyolojik bir durumdur ve farklı patolojik özelliklere sahiptir. ${ }^{[17]}$

Menisküs kisti etiyolojisinde son dönemde kabul edilen yeni teori ise, yırtık veya dejenere menisküs dokusu içinde eklem sıvısının lokal birikimi ile intrameniskal kistin oluştuğudur. ${ }^{[1]}$ Parameniskal kistlerin, eklem sıvısının menisküs yırtığı aracılığı ile (flep yırtığın tek yönlü valf etkisi) parameniskal yumuşak dokulara ulaşması ile oluştuğuna inanılır. ${ }^{[1,18-20]}$

\section{MENISKÜS KISTLERININ ÖZELLIKLERi}

Menisküs kistlerine sıklıkla horizontal menisküs yırtıkları eşlik eder. Mukopolisakkaritlerin interstisyel alanda birikimi menisküs yapısındaki kollajen liflerinden oluşan iskeleti zayıflatır; az sayıdaki vertikal uzanan kollajen lifinin hasar görmesi horizontal menisküs yırtığı oluşumuna zemin hazırlar (Şekil 1).[18] Başlangıçta vertikal liflerin hasarı ile intrameniskal

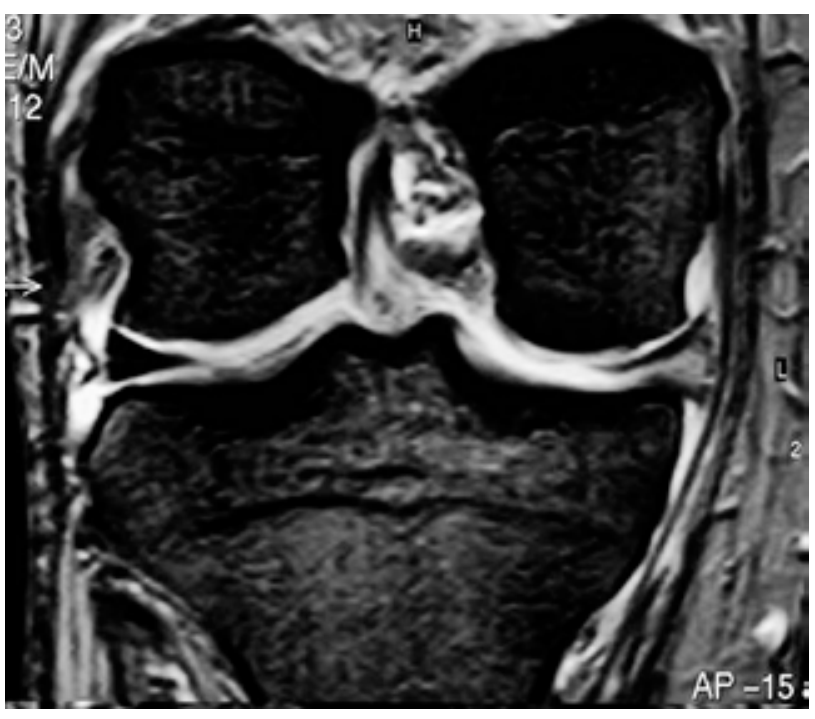

Şekil 1. Stromal mukoid dejenerasyon zemininde oluşmuş horizontal menisküs yırtığı.

yırtık oluşur ve bu intrameniskal yırtığın içi mukoid materyalle doludur. Bu alandaki MD zemininde oluşmuş intrameniskal yırtık eklemin santraline doğru uzanırsa, ekleme açılır ve dejenere zeminde oluşan horizontal menisküs yırtığı izlenir; şayet patoloji eklemin periferine yönelirse, mukoid materyal eklem periferinde birikerek parameniskal menisküs kisti oluşturur ve bu kistin intrameniskal yırtıkla doğrudan bağlantısı bulunur (Şekil 2). ${ }^{[5,6,9,19,21-23]}$ Menisküs yapısındaki bu intrameniskal yırtığın her iki tarafa ilerlemesiyle, horizontal menisküs yırtığının eşlik ettiği parameniskal kist izlenebilir. Özellikle lateral menisküste kistik ve stromal MD olgularına sık rastlanılır. ${ }^{[14]}$ Nadiren, menisküs kisti eklem boşluğuna açılmadan eklem içine doğru büyüyerek, genellikle interkondiller çentikte çapraz bağların çevresinde, intra-artiküler menisküs kistini oluşturur. ${ }^{[1,19]}$

Artroskopik ve cerrahi kayıtlar esas alındığında menisküs kistlerinin genelde dizin lateral kompartmanına yerleştiği bildirilmiş ${ }^{16,10,24-27]}$ olsa da, manyetik rezonans (MR) görüntüleme bulgularına göre dizin her iki kompartmanında da eşit sıklıkta tutulum olduğu gösterilmiştir. ${ }^{[28]}$ Bununla beraber, az sayıda çalışmada mediyal menisküs kistlerinin daha sık izlendiği de iddia edilmiştir (Şekil 3). ${ }^{[29,30]}$

Mediyal menisküste kistler sırasıyla, arka boynuz, ön boynuz ve menisküs gövdesi komşuluğunda sıklıkla izlenebilir.[1,19,30,31] Sıkı kapsüler bağlantılar nedeniyle, lezyon genellikle menisküs gövdesi içine hapsedilmiştir; palpe edilebilen kistik şişlikler 


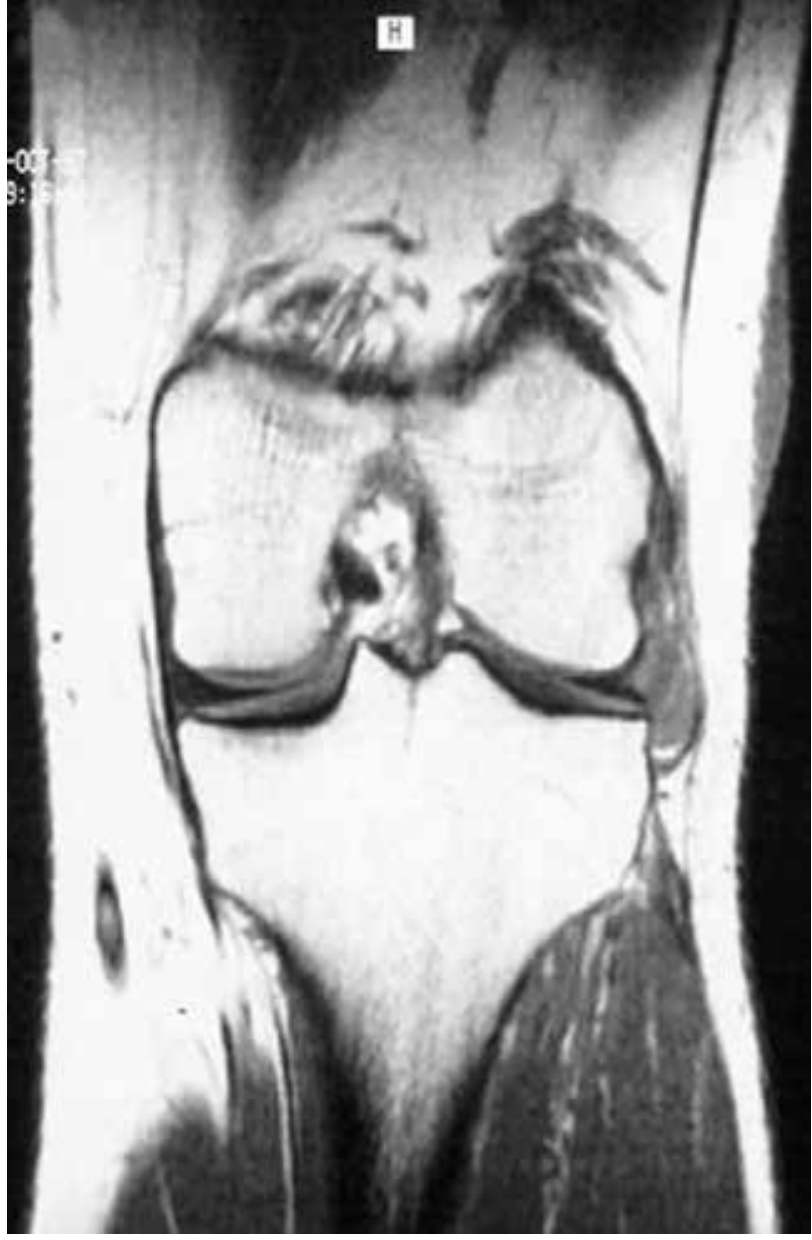

Şekil 2. Kistik parameniskal dejenerasyon. nadiren izlenir; oluştuğunda lateraldekilere göre daha büyüktür. ${ }^{[14]}$ Lateral menisküste ise en sık ön boynuz veya gövdeye yakın yerleşir; önde iliotibial bant, arkada dış yan bağ altında bulunur. ${ }^{[1,19,31]}$ Menisküs kistleri, nadirde olsa dizin interkondiler çentiğine, çapraz bağların yakınına doğru uzanabilir (intra-artiküler kist). ${ }^{[2,3]}$ Bu tip kistler basıya bağlı olarak kıkırdak hasarı da oluşturabilir. ${ }^{[2]}$

\section{KLINIK}

Menisküs kistleri genç yaş grubunda sık izlenir. ${ }^{[14]}$ Görülme sıklığı yaklaşık olarak \%7'dir. ${ }^{[9,32]}$ Menisküs kistleri semptom vermeyebilir (küçük boyutlu kistler), semptomatik olduğunda en önemli yakınma ağrıdır, palpasyonla hassasiyet ve genellikle dizin lateralinde şişlik saptanabilir. Mediyal menisküste kistler genelde menisküs gövdesine yerleştiği için kistik kitlenin oluşumu nadirdir; eğer kist gelişirse mediyal menisküs arka boynuzundan kaynaklanır ve dizin posteromediyalinde palpe edilir. ${ }^{[33]}$ Görülebilen ve palpe edilebilen kistik şişliklerin tanınması zor olmasa da gangliyon kisti, bursit, artritik çıkıntılar, serbest cisimler, menisküs yırtıkları ve tümör, ayırıcı tanı için dikkatle değerlendirilir. ${ }^{[9,34-39]}$ Pisani ${ }^{[40]}$, eklem çizgisinde palpe edilebilen lateral menisküs kistlerinin diz $20-30^{\circ}$ fleksiyonda iken belirgin hale geldiğini, ileri fleksiyon derecelerinde ise tibianın rotasyonuna bağlı olarak gözden kaybolduğunu bildirmiştir (Pisani bulgusu). Ayrıca dizin $45^{\circ}$ fleksiyona getirilmesini takiben tibianın dış

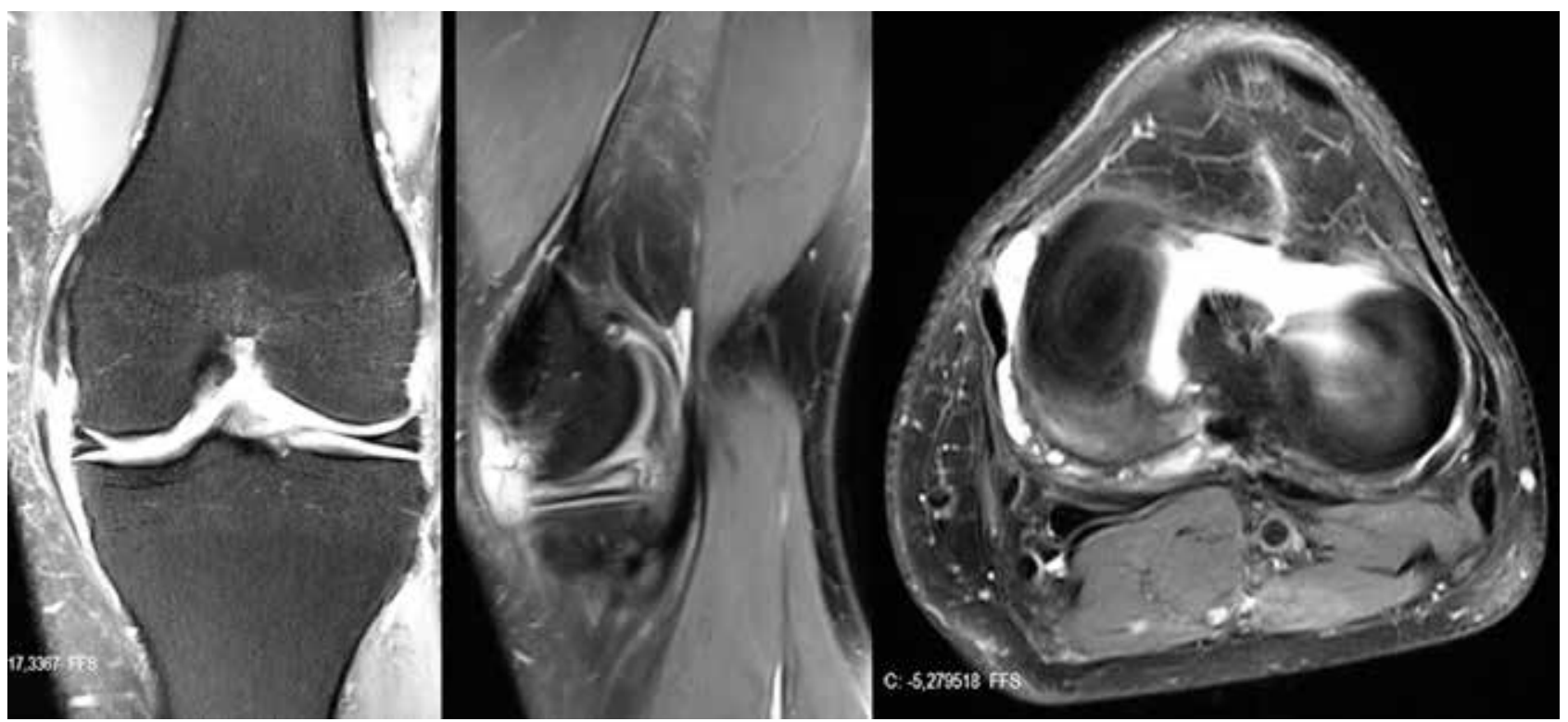

Şekil 3. Atipik yerleşimli bir mediyal menisküs kisti. 

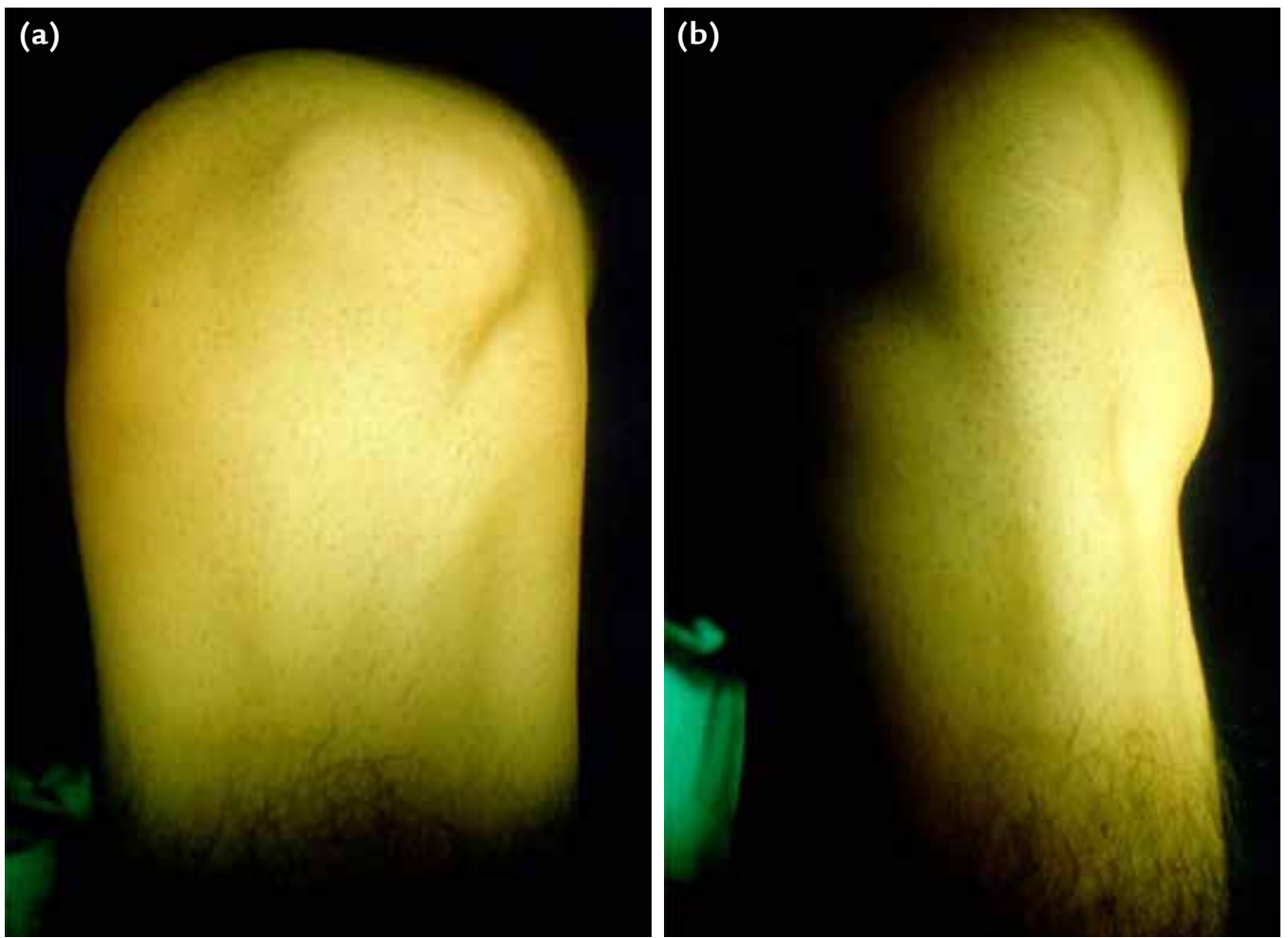

Şekil 4. a, b. $\operatorname{Diz} 45^{\circ}$ fleksiyonda tibia iç rotasyonda iken kistin yitmesi (a) ve dış rotasyonda iken lateral menisküs kistinin daha belirgin hale gelmesi (b).

rotasyonu ile kistin belirgin hale gelmesi ve tibianın iç rotasyonu ile gözden kaybolması, lateral menisküs kisti için tanı koydurucudur (Şekil 4). ${ }^{[34]}$ Menisküs yırtığına bağı takılma ve kilitlenme gibi mekanik semptomlar da tabloya eşlik edebilir. Lateral menisküs kisti basısına bağlı olarak peroneal sinir felci olguları, nadir de olsa bildirilmiştir. ${ }^{[41,42]}$

\section{RADYOLOJi}

Direkt radyografiler, menisküs kistinin tanısı için yapılan radyolojik çalışmaların içinde yer almasa da, kistin kronik basısına bağlı osseöz erozyonları gösterebilir. ${ }^{[43-45]}$ Tanısal çalışmada ultrasonografi (US) de yardımcı olabilir. ${ }^{[46]}$ Menisküs kistinin kesin tanısının konulmasında, kistin MR görüntüsü son derece önemli rol oynar. ${ }^{[2]}$ Menisküs yapısı proton dansite, $\mathrm{T}_{1}$ ağırlıklı görüntülerde iyi değerlendirilse de, patolojiyi en iyi $T_{2}$ ağırlıklı görüntüler gösterir. ${ }^{[47]} M R$ 'de menisküs yapısı içinde izlenen anormal sinyal artışı MD varlığını işaret eder; bu, üç evreli bir sınıflama ile değerlendirilir: Evre 1'de menisküs yapısında oval sinyal artışı gözlenirken, Evre 2'de çizgisel sinyal artışı bulunur; ortak özellikleri MR kesitindeki menisküs sınırları içine hapsolmuş olmalarıdır. Evre 3'te ise artmış olan intrameniskal sinyal ekleme uzanır; menisküs parankimal sınırı bu noktada kırılmıştır ki bu görüntü menisküs yırtığını ifade eder. ${ }^{[48]}$ İntrameniskal sinyal artışının bir ya da birden çok kesitte menisküs parankimal sınırlarını bozmaksızın tüm menisküsü kapsadığı görülebilir; bu durumda menisküs pencereye benzetilir ve bu, "pencere" veya "çerçeve" menisküs olarak anılır (Şekil 5). ${ }^{[14]}$ Menisküs kistleri $T_{2}$ ağırlıklı görüntülerde hiperintens olarak izlenir; kist sıvısının kaybı veya kist içine kanama olması hipointens görüntü oluşumuna sebep olur. $T_{1}$ ağırlıklı görüntülerde yoğunluğu belirleyen, kist sıvısının protein içeriğidir; protein içeriğin arttığı durumlarda görünüm iskelet kası yoğunluğu ile benzerdir. ${ }^{[49]}$

\section{ARTROSKOPIK BULGULAR}

Meniskal mukoid dejenerasyonun belirgin olduğu, intrameniskal yırtığın ekleme açılmadığı olgularda menisküsün yapısal bütünlüğü korunsa da biriken mukoid materyal varlığına bağlı olarak menisküs sarı renkte izlenebilir. ${ }^{[14]}$ Menisküs yırtığının eşlik ettiği menisküs kisti olgularında menisküs normal renkte izlenebilir, ancak menisküs eksizyonu ile birlikte sarı renkle karşılaşılması tipiktir (Şekil 6). ${ }^{[14]}$ 


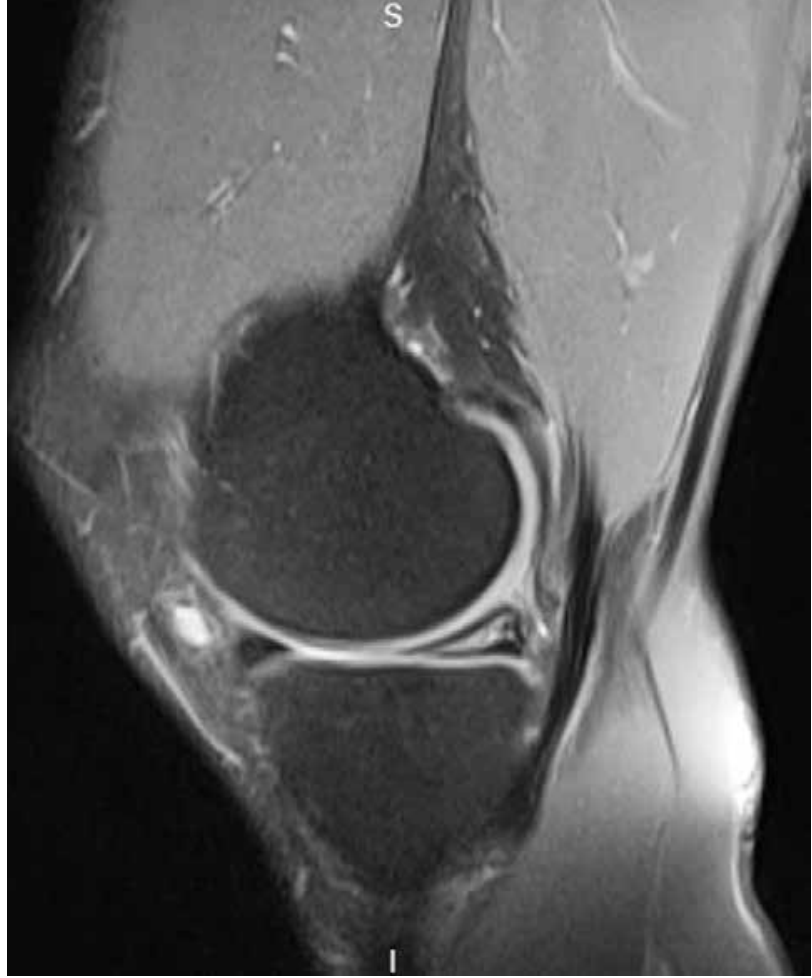

Şekil 5. MR görüntülemede "Pencere veya çerçeve menisküs" bulgusu.

Menisküs kistlerine, sıklıkla horizontal menisküs yırtığı eşlik eder (Şekil 7). ${ }^{[18]}$ Buna karşın, longitudinal, flep tarzı, radyal ve kompleks yırtıklarla da karşılaşılabilir. ${ }^{[14]}$

\section{AYIRICI TANI}

Gangliyon, bursit, proksimal tibiofemoral eklem kisti, sinoviyal kondromatozis gibi kisti taklit eden durumlar, lipom ve sinoviyal sarkom gibi solid lezyonların ayırıcı tanıda düşünülmesi gerekir. ${ }^{[9,21,35-39,50]}$

\section{TEDAVi}

Tarihsel gelişimi göz önüne alındığında tedavi seçenekleri;

a. Açık cerrahi ile kist eksizyonu. ${ }^{[23]}$

b. Açık cerrahi ile kist eksizyonu + açık total menisektomi. ${ }^{[22,27,35,39]}$

c. Menisküs lezyonunun artroskopik tedavisi + açık cerrahi ile kist eksizyonu. ${ }^{[37-38,51]}$

d. Menisküs lezyonu ve kistin artroskopik tedavisi (intra-artiküler dekompresyon). ${ }^{[22,52-55]}$

e. Artroskopik marsupializasyon. ${ }^{[20]}$
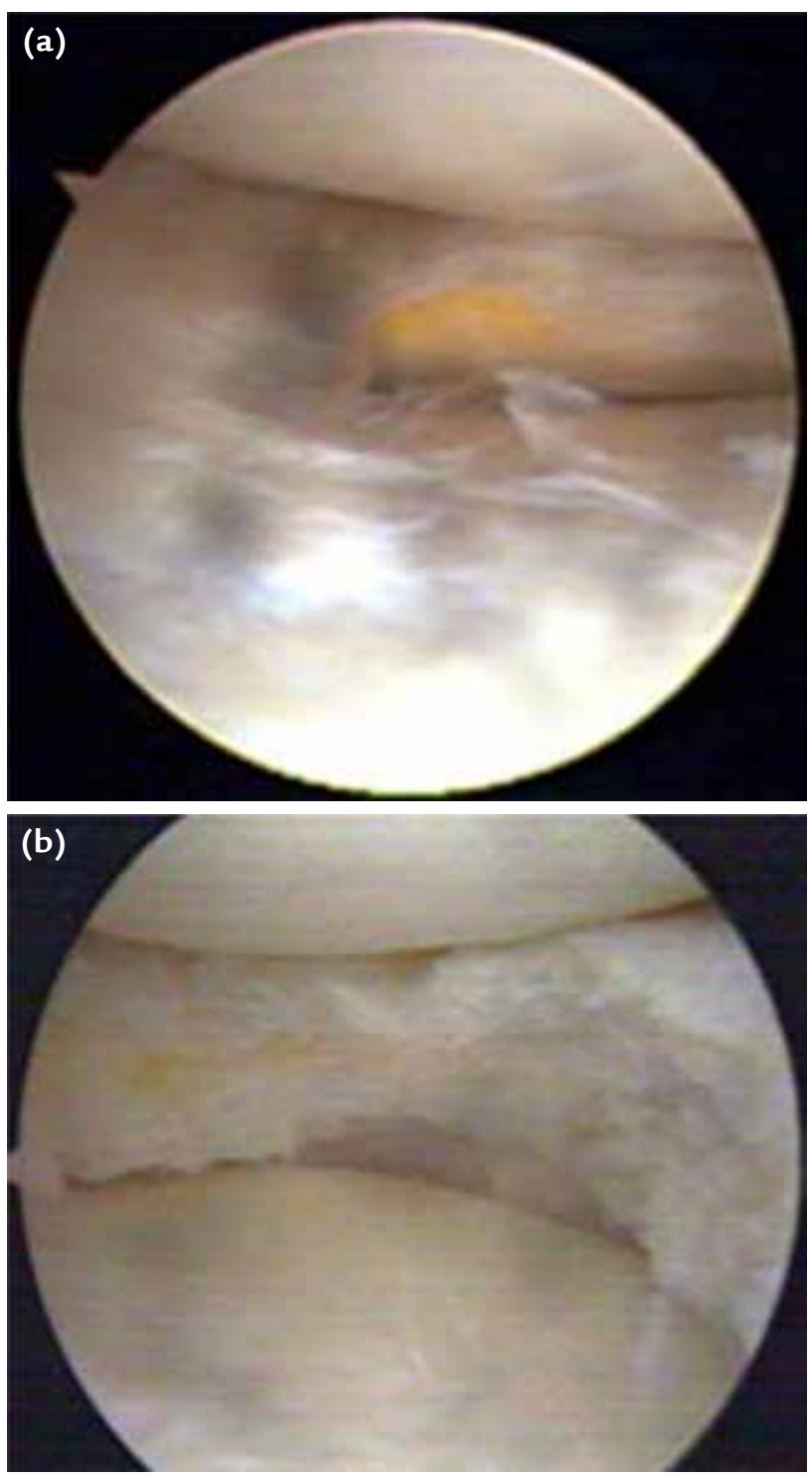

Şekil 6. a, b. Parsiyel menisektomi sonrası meniskal mukoid dejenerasyon bölgesindeki sarı renkli görünüm.

Menisküs kistinin tedavisi sırasında, eşlik eden menisküs yırtıklarının da tedavisi hedeflenmelidir. ${ }^{[56]}$ Açık cerrahi ile kist eksizyonu sonrasında sıklıkla nüks izlenir. ${ }^{[22,35,57]}$ Diz ekleminin sağkalımında menisküsler hayati önem taşıdıkları için, açık yöntemle total menisküs eksizyonu düşünülmez. Menisküs lezyonunun artroskopik tedavisi ile beraber açık cerrahi yöntemle kist eksizyonu sonrasında tatminkar sonuçlar bildirilmiştir. ${ }^{[37,38,51]}$ Bu teknikte, eşlik eden menisküs yırtığı menisküsün periferi korunacak şekilde artroskopik yolla tedavi edilirken (parsiyel menisektomi), perkütan yolla kiste dıştan-içe sokulan motorize traşlıyıcılarla kist dekompresyonu yapılır (Şekil 8). ${ }^{\left[{ }^{[8]} \text { Mediyal }\right.}$ 


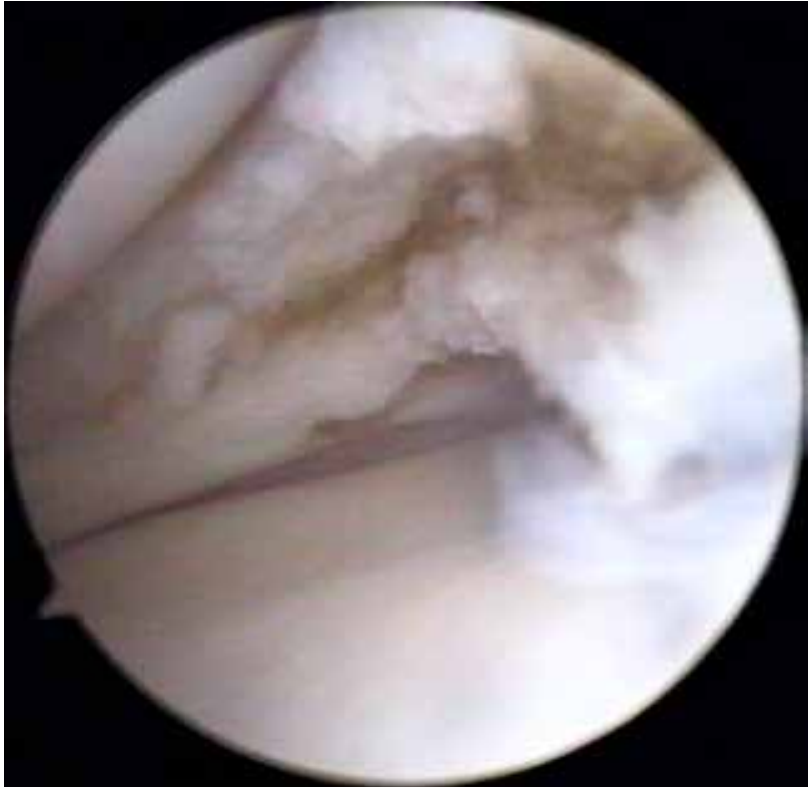

Şekil 7. Horizontal menisküs yırtı̆̆ı.

menisküs arka boynuzundan kaynaklanan menisküs kistlerinin artroskopik tedavisinde, posteromediyal portal ve posterior transseptal yaklaşım tekniği kullanılabilir. ${ }^{[59]}$ Menisküs lezyonunun ve menisküs kistinin artroskopik tedavisi (parsiyel menisektomi - kist dekompresyonu) etkili bir tedavi seçeneğidir. ${ }^{21,52-55]}$ Parameniskal menisküs kistine, yırtık bölgesinden, yırtığın eksizyonunu takiben intrameniskal yolla veya meniskokapsüler bağlantı bölgesinden yapılan sınırlı menisektomi aracılığı ile ulaşılabilir. Ancak, kist dekompresyonu için aşırı menisektomi yapılmasına ihtiyaç duyulabilir. ${ }^{[53-55]}$ Önerilen, eklemle kist arasında 5 mm'lik bir bağlantı yolu oluşturacak şekilde minimal menisektomi yapılmasıdır. ${ }^{\left[{ }^{[0]}\right.}$ Meniskokapsüler bileşkedeki ayrılma $2 \mathrm{~cm}$ 'den fazlaysa, instabilite riskinden dolayı menisküs tamiri yapılmalıdır. ${ }^{[61]}$ Artroskopik marsupializasyon uygulamasında, menisküs dokusuna zarar vermeden eklem kapsülünden kist içine açılan pencere (inframeniskal/suprameniskal) aracılığı ile kistin dekompresyonu sağlanırken menisküs ve menisküs-kapsül bileşkesi korunur. ${ }^{[20,37,50]}$ Horizontal yırtıkların eşlik ettiği lateral menisküs ön boynuz kistlerinin artroskopik tedavisinde kullanılan inframeniskal portal, hem doğrudan kiste hem de yırtığın stabil olmayan alt yaprağına ulaşımı sağlar; menisküs ön boynuzu ve meniskokapsüler bağlantı korunur. ${ }^{[62]}$ Haklar ve ark. ${ }^{[63]}$, benzer bir uygulamada, motorize traşlıyıcının daha rahat kullanıldığı intra-artiküler portalı tanımlamışlar ve menisküsü korumuşlardır.

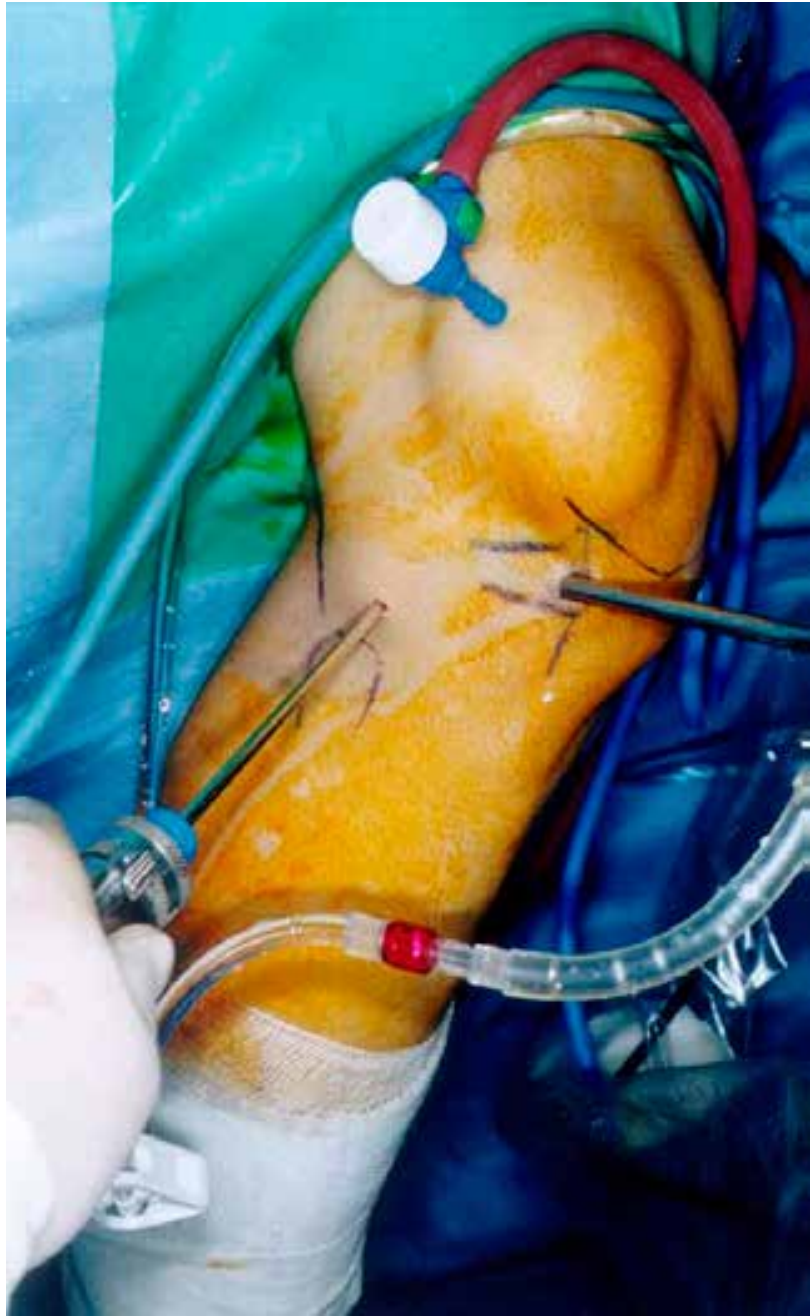

Şekil 8. İntrakistikportal kullanılarakyapılan kist dekompresyonu.

Menisküs kistine müdahale edilmeksizin izole olarak stabil kenar elde edilene kadar yapılan parsiyel menisektomi ile, diğer yöntemlerinkine benzer klinik sonuçların elde edilebileceği bildirilmiştir. ${ }^{[64]}$ Meniskal mukoid dejenerasyon zemininde oluşan menisküs yırtıklarının tedavisinde, şayet üst ve alt parçaların yapısı bozulmamışsa, vertikal dikişlerle tamir yapılması önerilmektedir. ${ }^{[65,66]}$ Menisküs kistinin artroskopik tedavisini takiben içten-dışa ve dıştan-içe yapılan kist dekompresyonunda uzun dönem takiplerde klinik sonuçlar benzerdir. ${ }^{[67,68]}$

US eşliğinde perkütan iğne aspirasyonu kısa ve orta dönem sonuçları başarılı, uygulaması kolay bir yöntem olarak sunulsa da, menisküs yırtığına yönelik (intrameniskal, intra-artiküler) müdahale olmamasından dolayı nüks olasılı̆̆ı yüksektir. ${ }^{[69,70]}$ 


\section{KAYNAKLAR}

1. Marra MD, Crema MD, Chung M, Roemer FW, Hunter DJ, Zaim S, Diaz L, Guermazi A. MRI features cystic lesions around the knee. Knee 2008;15(6):423-38. Crossref

2. Bhatti $A$, lqbal MJ. Pericruciate intra-articular lateral meniscal cyst without meniscal tear. Knee Surg Sports Traumatol Arthrosc 2006;14(9):869-71. Crossref

3. Letrakul N, Skaf A, Yeh L, Roger B, Schweitzer M, Blasbalg $\mathrm{R}$, Resnick D. Pericruciate meniscal cysts arising from tears of the posterior horn of the medial meniscus: MR imaging features that simulate posterior cruciate ganglion cysts. AJR Am J Roentgenol 1999;172(6):1575-9. Crossref

4. Lu CY, Hiseh TJ, Huang HT, Wang CK, Liu GC. A case report of unusual location of pericruciate meniscal cyst with adjacent bony erosion. Clin Imaging 2002;26(5):299-301. Crossref

5. Ferrer-Roca $O$, Vilalta $C$. Lesions of the meniscus. I. Macroscopic and histologic findings. Clin Orthop Relat Res 1980;(146):289-300. Crossref

6. Ferrer-Roca O, Vilalta C. Lesions of the meniscus. II. Horizontal cleavages and lateral cysts 1980;(146):301-7. Crossref

7. Romanini L, Calvisi V, Collodel M, Masciocchi C. Cystic degeneration of the lateral meniscus. Pathogenesis and diagnostic approach. Ital J Orthop Traumatol 1988;14(4):493-500.

8. McDevitt CA, Muir $\mathrm{H}$. Biochemical changes in the cartilage of the knee in experimental and natural osteoarthritis in the dog. J Bone Joint Surg Br 1976;58-B(1):94-101. Crossref

9. Smillie IS. Surgical pathology of the menisci. In: Smillie IS, editor. Injuries of the Knee Joint. Edinburgh: Churchill Livingstone; 1978. p.83-111.

10. Ollerenshaw R. The development of cyst in connection with the external semilunar cartilage of the knee-joint. Br J Surg 1921;8(32):409-12. Crossref

11. Hernandex FJ. Cysts of the semilunar cartilage of the knee: a light and electron microscopic study. Acta Orthop Scand 1976;47(4):436-40. Crossref

12. Walter JB, Talbot IC. Connective tissue: its normal structure and the effects of disease. In: Walter JB, Talbot IC, editors. General Pathology. Edinburgh: Churchill Livingstone; 1996. p.103-16.

13. Kleinberg S. Cysts of external semilunar cartilage: report of three cases. Arch Surg 1938;37(5):827-34. Crossref

14. Boya H, Pınar H, Gülay Z, Oktay G, Özer E. Clinical and arthroscopic features of the meniscal tears and search for the role of infection in histologically confirmed meniscal mucoid degeneration. Knee Surg Sports Traumatol Arthrosc 2004;12(4):294-9. Crossref

15. Fink C, Fermor B, Weinberg JB, Pisetsky DS, Misukonis MA, Guilak F. The effect of dynamic mechanical compression on nitricoxide production in themeniscus. Osteoarthritis Cartilage 2001;9(5):481-7. Crossref

16. Hashimoto S, Takahashi K, Ochs RL, Coutts RD, Amiel D, Lotz M. Nitric oxide production and apoptosis in cells of the meniscus during experimental osteoarthritis. Arthritis Rheum 1999;42(10):2123-31. Crossref

17. McDevitt CA, Webber RJ. The ultrastructure and biochemistry of meniscal cartilage. Clin Orthop Relat Res 1990;(252):818. Crossref

18. McCarthy CL, McNally EG. The MRI appearance of cystic lesions around the knee. Skeletal Radiol 2004;33(4):187209. Crossref

19. Beaman FD, Peterson JJ. MR imaging of cysts, ganglia, and bursae about the knee. Magn Reson Imaging Clin N Am 2007;15(1):39-52. Crossref
20. Howe TS, Koh JS. Arthroscopic internal marsupialization of meniscal cysts. Knee 2007;14(5):408-10. Crossref

21. Seger BM, Woods W. Arthroscopic management of lateral meniscal cysts. Am J Sports Med 1986;14(2):105-8. Crossref

22. Breck LW. Cysts of semilunar cartilages of the knee. Clin Orthop Relat Res 1954;3:29-38.

23. Flynn M, Kelly JP. Local excision of cyst of lateral meniscus of knee without recurrence. J Bone Joint Surg Br 1976;58B(1):88-9. Crossref

24. Burgan DW. Arthrographic finding in meniscal cysts. Radiology 1971;101(3):579-81. Crossref

25. Maffulli N, Petricciuolo F, Pintore E. Lateral meniscal cyst: arthroscopic management. Med Sci Sports Exerc 1991;23(7):779-82. Crossref

26. Parisien JS. Arthroscopic treatment of cysts of the menisci. A preliminary report. Clin Orthop Relat Res 1990;(257):154-8. Crossref

27. Taylor $\mathrm{H}$. Cysts of the fibrocartilage of the knee joint. J Bone Joint Surg 1935;17:588-96.

28. Tasker AD, Ostlere SJ. Relative incidence and morphology of lateral and medial meniscal cysts detected by magnetic resonance imaging. Radiology 1995;50(11):778-81. Crossref

29. Burk DL Jr, Dalinka MK, Kanal E, Schiebller ML, Cohen EK, Prorok RJ, Gefter WB, Kressel HY. Meniscal and ganglion cysts of the knee: MR evaluation. AJR Am J Roentgenol 1988;150(2):331-6. Crossref

30. Campbell SE, Sanders TG, Morrison WB. MR imaging of the meniscal cysts: incidence, location, and clinical significance. AJR Am J Roentgenol 2001;177(2):409-13. Crossref

31. De Maeseneer M, Shahabpour M, Vanderdood K, Machiels F, De Ridder F, Osteaux M. MR imaging of meniscal cysts: evaluation of location and extension using three-layer approach. Eur J Radiol 2001;39(2):117-24. Crossref

32. Barrie $\mathrm{HJ}$. The pathogenesis and significance of meniscal cysts. J Bone and Joint Surg Br 1979;61-B(2):184-9. Crossref

33. Hulet C, Kopf S, Rochcongar G, Roland B. Meniscal Cysts. In: Hulet C, Pereira H, Peretti G, Denti M, editors. Surgery of the Meniscus. ESSKA: Springer; 2016. p.237-50.

34. Pinar $\mathrm{H}$, Boya $\mathrm{H}$, Satoglu IS, Oztekin HH. A contribution to Pisani's sign for diagnosing lateral meniscal cysts: a technical report. Knee Surg Sports Traumatol Artrosc 2009;17(4):4024. Crossref

35. Bonnin JG. Cyst of semilunar cartilage of the knee-joint. Br J Surg 1953;40(164):558-65. Crossref

36. Lantz B, Singer KM. Meniscal cysts. Clin Sports Med 1990;9(3):707-25.

37. Pedowitz RA, Feagin JA, Rajagopalan S. A surgical algorithm for treatment of cystic degeneration of the meniscus. Arthroscopy 1996;12(2):209-12. Crossref

38. Regan WD, McKonkey JP, Loomer RL, Davidson RG. Cysts of lateral meniscus: arthroscopy versus arthroscopy plus open cystectomy. Arthroscopy 1989;5(4):274-81. Crossref

39. Wroblewski BM. Trauma and cystic meniscus: review of 500 cases. Injury 1973;4(4):319-21. Crossref

40. Pisani AJ. pathognomic sign for cyst of the cartilage. Arch Surg 1947;54(2):188-90. Crossref

41. Jowett AJL, Johnston JFA, Gaillard F, Anderson SE. Lateral meniscal cyst causing common peroneal palsy. Skeletal Radiol 2008;37(4):351-5. Crossref

42. Thompson AT, Gallacher PD, Rees R. Lateral meniscal cyst causing irreversible peroneal nerve palsy. J Foot Ankle Surg 2013;52(4):505-7. Crossref 
43. Enis JE, Ghandur-Mnaymneh L. Cyst of lateral meniscus causing erosion of the tibial plateau. A case report. J Bone Joint Surg Am 1979;61(3):441-2. Crossref

44. Al-Khateeb $\mathrm{H}$, Ruiz A. Lateral meniscal cyst producing lesion of the tibial plateau and literature review. Int J Surg 2008;6(5):412-4. Crossref

45. Thompson SM, Cross TM, Cross MJ, Wood DG. Medial meniscal cyst as a cause of painful erosion of the tibial plateau. Knee Surg Sports Traumatol Arthrosc 2016;24(5):1544-6. Crossref

46. Rutten MJ, Collins JM, Van Kampen A, Jager GJ. Meniscal cysts: detection with high-resolution sonography. AJR Am J Roentgenol 1998;171(2):491-6. Crossref

47. Howell R, Kumar NS, Patel N, Tom J. Degenerative meniscus: Pathogenesis, diagnosis, and treatment options. World J Orthop 2014;5(5):597-602. Crossref

48. Crues JV, Mink J, Levy TL, Lotysch M, Stoller DW. Meniscal tears of the knee: accuracy of MR imaging. Radiology 1987;164(2):445-8. Crossref

49. Burk Jr DL, Dalinka MK, Kanal E, Schiebler ML, Cohen EK, Prorok RJ, Gefter WB, Kressel HY.. Meniscal and ganglion cysts of the knee: MR evaluation. AJR Am J Roentgenol 1998;150(2):331-6. Crossref

50. Mountney J, Thomas NP. When is a meniscal cyst not a meniscal cyst? Knee 2004;11(2):133-6. Crossref

51. Mills CA, Henderson IJ. Cyst of the medial meniscus. Arthroscopic diagnosis and management. J Bone Joint Surg $\mathrm{Br}$ 1993;75-B(2):293-8. Crossref

52. Ferriter PJ, Nisonson $B$. The role of arthroscopy in the treatment of lateral meniscal cysts. Arthroscopy 1985;1(2):142-3. Crossref

53. Glasgow MM, Allen PW, Blakeway C. Arthroscopic treatment of cysts of the lateral meniscus. J Bone Joint Surg $\mathrm{Br} 1993 ; 75-$ $B(2): 299-302$. Crossref

54. Miotti M, Arena NE, De Angelis-Ricciotti F. Lateral meniscal cysts therapeutic problems. Ital J Orthop Traumatol 1993;19:353-8

55. Ryu RK, Ting AJ. Arthroscopic treatment of meniscal cysts. Arthroscopy 1993;9(5):591-5. Crossref

56. Pınar $\mathrm{H}$, Boya $\mathrm{H}$. Mucoid degeneration and cysts of the meniscus. In: Doral MN, Tandoğan RN, Mann G, Verdong $\mathrm{R}$, editors. Sport Injuries: Prevention, Diagnosis, Treatment and Rehabilitation. Berlin, Heidelberg: Springer-Verlag; 2012. p.297-300.

57. Gallo GA, Bryan RS. Cysts of semilunar cartilages of the knee. Am J Surg 1968;116(1):65-8. Crossref
58. Tudisco C, Meo A, Blasucci C, Ippolito E. Arthroscopic treatment of lateral meniscal cysts using an outside-in technique. Am J Sports Med 2000;28(5):683-6. Crossref

59. Herode P, Shroff A, Mandlewala V, Chaudhary A. Posttraumatic medial meniscal cyst in young: a case report. J Orthop Case Rep 2016;6(3):7-9. Crossref

60. Cowden $\mathrm{CH}$ 3rd, Barber FA. Meniscal cyst: treatment options and algorithm. J Knee Surg 2014;27(02):105-12. Crossref

61. Ahn JH, Wang JH, Yoo JC, Kim SK, Park JH, Park JW. The modified outside-in suture: vertical repair of anterior horn o the meniscus after decompression of a large meniscal cyst. Knee Surg Sports Traumatol Arthrosc 2006;14(12):1288-91. Crossref

62. Chen D, Li Q, Sun Y, Qin J, Yao Y, Jiang Q. Arthroscopic Management for the Unstable Inferior Leaf of the Lateral Meniscus Anterior Horn and Associated Cysts through a Direct Inframeniscal Portal: A Retrospective Study. Biomed Res Int 2017;2017:1-7. Crossref

63. Haklar U, Ayhan E, Ustundag S, Canbora K. A new arthroscopic technique for lateral parameniscal cyst decompression. Knee 2014;21(1):126-8. Crossref

64. Kumar NS, Jakoi AM, Swanson CE, Tom JA. Is formal decompression necessary for parameniscal cysts associated with meniscal tears? Knee 2014;21(2):501-3. Crossref

65. Kamimura T, Kimura M. Meniscal repair of degenerative horizontal cleavage tears using fibrin clots. Orthop J Sports Med 2014;2(11). Crossref

66. Kurzweil PR, Lynch NM, Coleman S, Kearney B. Repair of horizontal meniscus tears: a systematic review. Arthroscopy 2014;30(11):1513-9. Crossref

67. Sarimo J, Rainio P, Rantanen J, Orava S. Comparison of two procedures for meniscal cysts. A report of 35 patients with mean follow-up of 33 months. Am J Sports Med 2002;30(5):704-7. Crossref

68. El-Assal M, Mostafa M, Abdel-Aal A, El-Shafee M. Arthroscopy alone or in associated with open cystectomy: in treatment of lateral meniscal cysts. Knee Surg Sports Traumatol Arthrosc 2003;11(1):30-2. Crossref

69. Macmahon PJ, Brennan DD, Duke D, Forde S, Eustace SJ. Ultrasound-guided percutaneous drainage of meniscal cysts: preliminary clinical experience. Clin Radiol 2007;62(7):6837. https://doi.org/10.1016/j.crad.2007.02.007

70. Chang A. Imaging-guided treatment of meniscal cysts. HSS J 2009;5(1):58-60. Crossref 